- a normal commercial rapeseed oil-meal :

dry matter : 90 ; total crude protein : 39.0 ; fat : 2.7 ; ashes : 7.5 ; crude fibre : 12.2 ; I.T.C. (*) : 2.2 ; T.O.V. $\left({ }^{*}\right): 5.2$; gross energy $\mathrm{kcal} / \mathrm{kg}$ D.M. : 4664 ;

- a normal French low glucosinolate rapeseed oil-meal (Normal French Zerothio) :

dry matter : 89.5 ; total crude protein : 37.9 ; fat : 2.5 ; ashes : 7.5 ; crude fibre : 15.4 ; I.T.C. (*) : 0.85 ; T.O.V. $\left(^{*}\right): 1.58$; gross energy kcal/kg D.M. : 4664 ;

- A French low glucosinolate dehulled rapeseed oil-meal (Dehulled French Zerothio) :

dry matter : 90.2 ; total crude protein : 42.1 ; fat : 7.2 ; ashes : 7.2 ; crude fibre : 6.9 ; I.T.C. $\left(^{*}\right)$ : 1.48 ; T.O.V. $\left({ }^{*}\right): 2.38$; gross energy kcal/kg D.M. : 4900 .

The trial involved 16 castrated male pigs with a mean live weight of $59.8 \mathrm{~kg}$ distributed into 4 groups and housed in individual pens. Faecal collection was made during 10 consecutive days. The energy and protein value of rapeseed oil-meals was assessed using the substitution method with simplified diets based on maize, containing 10 p. 100 normal commercial rapeseed oil-meal (group 2) and 20 p. 100 normal French Zerothio rapeseed oil-meal (group 3) or dehulled (group 4). Group 1 received a diet only based on maize.

The digestible energy values estimated for the 3 types of rapeseed oil-meals, normal commercial, normal French Zerothio, and dehulled French Zerothio were 3569,3462 and $4181 \mathrm{kcal} / \mathrm{kg}$ D.M., corresponding to apparent energy digestibility coefficients of 77.1 ; 74.2 and 85.3. The apparent protein digestibility coefficients were 76.1 p. 100 for the commercial normal rapeseed oil-meal, 79.7 p. 100 for the normal French Zerothio and 88.1 p. 100 for the dehulled French Zerothio.

Our results showed that the apparent protein digestibility coefficient of the French low glucosinolate rapeseed oil-meal was improved by 5 p. 100 as compared to the normal commercial rapeseed oil-meal, but the most significant result was the large improvement of the nutritional value of the French low glucosinolate dehulled rapeseed oil-meal ( 20 p. 100 for digestible energy and 15 p. 100 for protein A.D.C. mainly due to a reduction by 8.5 points of its crude fibre content as compared to normal rapeseed oil-meal.

\title{
Utilization of sweet kalina lupin seed in weaned piglets and growing-finishing pigs
}

\author{
J. CASTAING *, R. COUDURE *, J. FEKETE **, F. GROSJEAN **, \\ M. LEUILLET ** \\ *Association générale des Producteurs de Maïs, \\ 122 , boulevard Tourasse, F 64000 Pau \\ ** Institut technique des Céréales et des Fourrages, \\ 8, avenue du Président-Wilson, F 75116 Paris
}

Two experiments were made in young piglets of 8.4 to $23 \mathrm{~kg}$ and in bacon pigs of 26.3 to $104 \mathrm{~kg}$ in order to study the effect of relatively low levels in incorporation of white soft lupin of the variety Kalina. The maximum level was 10 points for piglets and 15 points for bacon pigs.

In piglets, utilization of lupin in diets offered as a meal containing $3150-3200 \mathrm{kcal}$ D.E. and supplying $360 \mathrm{~g}$ lysine for $1000 \mathrm{kcal}$ digestible energy did not allow to reach the performance obtained with the control diet. An almost linear decrease in the feed intake ranging around 15 p. 100 , was observed with the level of 10 points lupin. Growth rates were reduced less than proportional to the levels of feed intake since the feed conversion ratio was slightly improved by the presence of lupin.

(*) Expressed in $\mathrm{mg} / \mathrm{g}$ of defatted dry matter. 
For the bacon pigs subjected to restricted feeding with diets containing $3300 \mathrm{kcal}$ D.E. supplying 2.50 to $2.60 \mathrm{~g}$ lysine for $1000 \mathrm{kcal}$ D.E. and offered in the trough as a moistened meal, the presence of 5 points lupin did not alter the performance as compared to the control diet only composed of maize and soybean meal. At the level of 10 points, a decrease in growth rate as well as a 4 p. 100 increase in the feed conversion ratio were observed over the whole fattening period. These discrepancies only occurred during the finishing period. At the level of 15 points the performance were highly reduced (by 10 p. 100) and the animals exhibited flatulence troubles accompanied by a reduced appetite. Use of flax seeds as curative or preventive treatment undoubtedly reduced the magnitude of these phenomena, which are probably due to the bad digestion of alphagalactosides whose proportion is rather high in this type of lupin (8 p. 100 stachyose).

A reduction in the carcass yield was noticed in pigs fed lupin containing diets but it has to be pointed out that 10 and 15 points lupin led to an improvement of the body composition.

\title{
Nutritional value of whole extruded soyabean seeds in piglet feeding
}

\author{
A. AUMAITRE, D. BOURDON \\ INV.R.A., Station de Recherches sur l'Elevage des Porcs, \\ Centre de Rennes-Saint-Gilles, F 35590 L'Hermitage
}

Soybean oil-meal intended for monogastric animals has to be subjected to heat treatments so as to improve its nutritional value. Possible use of whole soybean seeds gives rise to a double problem involving the presence of antinutritional factors and a high lipid level. Moreover, only little accurate information is available on the possible use of such a feed in early weaning diets for piglets.

This experiment allowed to compare a classical diet composed of maize-soybean meal (70 and 22 p. 100) with a almost isoenergic diet composed of barley, a moderately energy rich cereal associated with whole extruded soybean seed $(67$ and 25 p. 100). Piglet performance measured between 5 and 10 weeks of age showed that whole extruded seed which contained less than 0.8 ITU of antitrypsine factor per $\mathrm{mg}$ was as valuable a protein source as soybean meal. Both diets were equally consumed (866 versus $876 \mathrm{~g} /$ day) and the daily mean gain was similar for both treatments (444 versus $447 \mathrm{~g}$ /day). Feed conversion ratios were identical (1.95 versus $1.94 \mathrm{~kg}$ of diet per $\mathrm{kg}$ weight gain). A supplementary isoenergetic diet based on barley-soybean-meal and tallow led to equivalent mean performance.

However, the adaptation of the animals varied according to diet composition. Performances during the different periods between 8.4 and $24 \mathrm{~kg}$ were discussed. Conclusions were drawn as regards the efficiency of the extrusion in suppressing antinutritional factors and the economic conditions of the use of whole soybean seeds in weaning diets for piglets.

\section{Choice of the protein sequence during post-weaning (ad libitum) and fattening periods (restricted)}

\author{
F. GROSJEAN *, J. CASTAING **, O. LAVOREL *, M. LEUILLET * \\ * I.T.C.F., 8, avenue du Président-Wilson, F 75116 Paris \\ ** A.G.P.M., 122, boulevard Tourasse, F 64000 Pau
} $103 \mathrm{~kg}$.

Two experiments were carried out with 256 Large White pigs weighing from 9 to

In the first experiment we studied the subsequent effect of the post-weaning protein level $(21$ or 18 p. 100 crude protein) on bacon pigs receiving a suitable level of protein (18 p. 100). The following sequences were compared : 21-18 and 18-18. 